NBER WORKING PAPER SERIES

\title{
TRANSITION DYNAMICS IN VINTAGE CAPITAL MODELS: EXPLAINING THE POSTWAR CATCH-UP OF GERMANY AND JAPAN
}

\author{
Simon Gilchrist \\ John C. Williams \\ Working Paper 10732 \\ http://www.nber.org/papers/w10732
}

\author{
NATIONAL BUREAU OF ECONOMIC RESEARCH \\ 1050 Massachusetts Avenue \\ Cambridge, MA 02138 \\ August 2004
}

We thank Joanna Wares and Adam Litwin for excellent research assistance. This paper benefitted from discussions with Larry Christiano, Russell Cooper, Jonathon Eaton, Peter Klenow, Sam Kortum, John Leahy, and participants at the NBER Summer Institute, the AEA Annual Meeting, the NBER Economic Fluctuations and Growth Meeting, and presentations at the Bank of England, Boston University, the Council of Economic Advisers, CREST, the Federal Reserve Banks of Boston, Minneapolis, and New York, New York University, University of Paris I : Pantheon-Sorbonne, University of Texas at Austin, and the University of Virginia. We also thank the National Science Foundation for financial support (SES-9876548). The opinions expressed here are not necessarily shared by the management of the Federal Reserve Bank of San Francisco. The views expressed herein are those of the author(s) and not necessarily those of the National Bureau of Economic Research.

(C2004 by Simon Gilchrist and John C. Williams. All rights reserved. Short sections of text, not to exceed two paragraphs, may be quoted without explicit permission provided that full credit, including (C) notice, is given to the source. 
Transition Dynamics in Vintage Capital Models: Explaining the Postwar Catch-Up of Germany and Japan

Simon Gilchrist and John C. Williams

NBER Working Paper No. 10732

August 2004

JEL No. D24, E22, N10, O41

\begin{abstract}
We consider a neoclassical interpretation of Germany and Japan's rapid postwar growth that relies on a catch-up mechanism through capital accumulation where technology is embodied in new capital goods. Using a putty-clay model of production and investment, we are able to capture many of the key empirical properties of Germany and Japan's postwar transitions, including persistently high but declining rates of labor and total-factor productivity growth, a U-shaped response of the capitaloutput ratio, rising rates of investment and employment, and moderate rates of return to capital.

Simon Gilchrist

Boston University

270 Bay State road

Boston, MA 02215

and NBER

sgilchri@bu.edu

John C. Williams

Federal Reserve Bank of San Francisco

101 Market Street

San Francisco, CA 94105

john.c.williams@sf.frb.org
\end{abstract}




\section{Introduction}

Per capita GDP increased by over 5 percent per year in Germany in the 1950s and 1960s and over 8 percent per year in Japan; the corresponding figure for the United States was 2 percent. What accounts for the remarkable performance of these "economic miracles"? A variety of explanations have been put forward, many of which emphasize the roles played by cultural, institutional, and political factors. Another strain of the literature, which we pursue in this paper, has emphasized the more prosaic processes of capital accumulation and technological change as driving forces for the rapid postwar growth of the German and Japanese economies. ${ }^{1}$ Outside of growth-accounting exercises, however, there has been little quantitative research evaluating this explanation in light of the empirical evidence.

One hypothesis that has been subjected to scrutiny and been founded wanting is that the postwar growth experiences of Germany and Japan are consistent with the predictions of a simple optimizing growth model where the initial capital stock is well below its steady-state level. In his study of Japanese saving behavior, Hayashi (1989) documents the U-shape of the time series of the wealth-to-income ratio in postwar Japan and argues that it is inconsistent with the simple capital accumulation hypothesis. Christiano (1989) further argues that one can explain neither the delayed response of Japanese saving and growth rates nor the long duration of the catch-up process without substantial modifications to the baseline growth model. Finally, King and Rebelo (1993) note that if capital accumulation is an important contributor to Germany and Japan's postwar growth, a standard growth model implies either extremely high real interest rates or extraordinarily high values of installed capital in the early stages of development; neither prediction appears to hold true in either country.

The rates of investment, unemployment, and productivity growth in postwar Germany and Japan also are at odds with the predictions of a standard optimizing growth model with a low initial capital stock. According to such a model, the investment share of GDP should initially soar and then decline monotonically as capital deepening takes place. In Germany and Japan, however, investment rates started low and then rose. The standard optimizing model also implies that the effects of low labor productivity and a high return to capital will have offsetting

\footnotetext{
${ }^{1}$ See, for example, Maddison (1964), Ohkawa and Rosovsky (1968), Denison and Chung (1976), and Hulten (1991).
} 
influences on employment during the early stage of development, with the result that employment remains near its steady-state level during the transition. In fact, the West German unemployment rate exceeded 10 percent in 1950, before gradually falling to below 2 percent by 1960. The situation was similar in Japan, where a significant degree of underemployment - manifested by relatively high employment in traditional agricultural and craft sectors - persisted through the 1950s (Denison and Chung (1976)). Finally, an explanation based solely on an initial shortfall of capital predicts that labor productivity growth occurs simultaneously with growth in the capital-labor ratio. This contradicts the empirical finding that the peak in labor productivity growth preceded that in capital deepening in both countries.

A second, more promising, hypothesis is that Germany and Japan's postwar transitions reflected the closing of a gap in technology between these countries and the United States. Total factor productivity (TFP) in German manufacturing was about half that in the United States in 1950, and manufacturing TFP in Japan was only a third the U.S. level in 1955 (van Ark and Pilat (1993)). This gap narrowed considerably over the next three decades: By 1980, TFP in German manufacturing had risen to 80 percent of the U.S. level and in Japan it had reached 60 percent of the U.S. level. Christensen, Cummings and Jorgenson (1981) find similar results using TFP measured on the basis of the entire economy. We argue that a significant portion of the initial technology gap resulted from the use of prewar and wartime industrial machinery and production processes far less efficient than modern technologies available in the United States. In our view, German and Japanese postwar investment in capital goods embodying modern production technologies gradually closed this "machine gap." ${ }^{2}$ A natural outcome of this process of capital accumulation with embodied technology is a gradual diffusion of productivity gains over time.

We argue that the observed patterns of investment, employment, and productivity growth in Germany and Japan in the 1950s and 1960s are consistent with a growth model based on a putty-clay production technology and capital accumulation with embodied technological change. The process of technological catchup was slowed by the putty-clay nature of capital. The relative fixity of existing

\footnotetext{
${ }^{2}$ An alternative explanation for this transformation is that an "idea gap" that was not embodied in the capital stock existed at the end of the war, and that this gap eroded over time. For example, Parente and Prescott (1994) and Eaton and Kortum (1997) argue that the postwar pattern of initially high, then falling, TFP growth results from the gradual diffusion of technological and organizational knowledge from the United States to Germany and Japan.
} 
capital-labor ratios intrinsic to putty-clay capital implies that it is costly to rapidly increase employment and production. As a result, capital accumulation initially occurs through a process of "capital widening" that expands employment and productive capacity with relatively low rates of investment. During this phase of the transition, productivity growth is high, owing to the effects of embodied technology, but the rate of capital accumulation is relatively low, and, as a result, the capitaloutput ratio falls. Over time, the economy builds sufficient capacity to engage in standard capital deepening. During this latter phase of the transition, productivity growth slows while the rate of capital accumulation rises.

The remainder of the paper is organized as follows. Section 2 provides a discussion of the German and Japanese economic performance in the three decades following the Second World War. Section 3 presents a dynamic general equilibrium model that incorporates putty-clay capital and embodied technology. In section 4 the transition dynamics of the model are analyzed and compared to the empirical evidence documented in section 2. Section 5 concludes.

\section{Germany and Japan's Postwar Growth Experiences}

Germany and Japan's postwar growth experiences can be divided into three distinct periods: an initial phase of immediate postwar reconstruction; an early stage of technological catch-up marked by rapid increases in productivity and relatively low rates of capital accumulation; and a later phase of technological catch-up marked by declining rates of productivity growth and high rates of capital accumulation.

\subsection{Stages of Growth}

In the immediate postwar period of reconstruction, the economies of Germany and Japan experienced rapid growth as they recovered from wartime conditions, damage and destruction to the capital stock and infrastructure, and the influx of millions of refugees. Although estimates of overall war-related capital destruction are inherently imprecise and mask the unequal distribution across sectors - for example, German heavy industry was particularly hard hit and Japan's shipping fleet was devastated a reasonable estimate is that about 20 to 25 percent of Germany's and Japan's capital stocks were destroyed or dismantled (Wolf (1993), Denison and Chung (1976)). In addition to capital destruction, both Germany and Japan experienced large population inflows owing to wartime displacement and postwar repatriation. From 1945 
to 1953, about 10 million people migrated into West Germany; this represented a 25 percent increase in its 1945 population (Wolf (1993)). Some 8 million people repatriated to Japan, adding about 10 percent to the population (Denison and Chung (1976)). Combining the effects of capital destruction and immigration in the immediate postwar period, and taking into account investment during this period, the capital shortfall in each country was probably on the order of 20 percent as of the early 1950s.

The period of immediate postwar reconstruction ended around 1950 in West Germany, and a few years later in Japan. ${ }^{3}$ Because the immediate postwar phase is so unusual and owing to the limited quality of available data, we exclude this period from the analysis in this paper. Instead, we limit ourselves to the two decades that follow, when both the German and Japanese economies had largely recovered from the immediate effects of wartime disruption and dislocation, but nonetheless experienced tremendous growth.

In the early stage of the process of catch-up - occurring primarily in the 1950s rates of return on capital were high in Germany and Japan, but business investment as a share of GDP was depressed. Table 1 shows total real rates of return on equities and private business fixed investment as a share of GDP for various time periods for a number of countries. Not surprisingly, in light of the destruction of capital during the war, the rate of return during the 1950s was especially high in Germany (25 percent) and Japan (28 percent), relative to an (unweighted) average of 15 percent in the other countries reported in the table. Even with these high rates of return, the investment shares in Germany and Japan were well below their respective longer-run averages.

In the later stage of catch-up - occurring during the 1960s and 1970s - rates of return in Germany and Japan dropped back to levels roughly in line with those in other countries, and the investment shares in Germany and Japan rose in both countries. The average rate of return in Germany in the 1960s was in the middle

\footnotetext{
${ }^{3}$ In the case of Germany, fundamental economic and monetary reform was instituted in 1948, and the Federal Republic of Germany was established in 1949. By 1950 industrial production in Germany had reached its prewar peak and the process of repair and reconstruction of the damaged capital and infrastructure was mostly complete. This initial phase took somewhat longer in Japan, but was largely completed around 1953: Economic and monetary reform was initiated in 1949, and Japan regained its independence in 1952. Japanese industrial production reattained its prewar peak in 1954. In addition to the sources listed in the first footnote of this paper, references on the immediate postwar periods of Germany and Japan include Wallich (1955), Cohen (1958), Giersch, Paqué and Schmieding (1993), and Hamada and Kasuya (1993).
} 
Table 1: Rates of Return and Investment (average annual rates)

\begin{tabular}{lrrrrrrr}
\hline \hline & \multicolumn{3}{c}{ Rate of Return } & & \multicolumn{3}{c}{ Investment Share } \\
\cline { 2 - 4 } \cline { 6 - 8 } Country & $50-59$ & $60-69$ & $70-79$ & & $50-59$ & $60-69$ & $70-79$ \\
\hline Germany & 25 & 4 & -3 & & 14 & 17 & 16 \\
Japan & 28 & 9 & 3 & & 19 & 26 & 25 \\
USA & 16 & 6 & -1 & & 11 & 12 & 12 \\
France & 17 & 1 & -1 & & 14 & 18 & 16 \\
Italy & 20 & 0 & -12 & & 13 & 12 & 12 \\
UK & 14 & 7 & -1 & & 11 & 14 & 15 \\
Canada & 13 & 7 & 2 & & 17 & 17 & 16 \\
Sweden & 11 & 4 & -2 & 15 & 17 & 16 \\
\hline Notes: Rate of return is the ex post total return to equities, \\
taken from Dimson, Marsh and Staunton (2002). Investment \\
share denotes the ratio of business fixed investment to GDP, \\
from OECD (various). \\
\hline \hline
\end{tabular}

of the range of other countries, while that in Japan was a bit above that of other countries. The investment share in Japan rose 7 percentage points between the 1950s and 1960s, while that in Germany rose a more modest 3 percentage points. The investment share was roughly unchanged across the two decades in the other countries.

In the early stage of catch-up, aggregate TFP growth in Germany and Japan was very rapid, while capital-output ratios actually fell. Table 1 shows the growth rates of economy-wide TFP, the capital-labor ratio, and the capital-output ratio over three periods for Germany, Japan, and four other countries, taken from Wolff (1996). ${ }^{4}$ TFP growth during the 1950s averaged nearly 5 percent per year in both Germany and Japan, well above the rates seen in other European countries or the United States. In contrast, growth in the capital-labor ratio during the 1950s in Germany and Japan was on par with that in other countries. The combination of rapid TFP and a moderate pace of capital accumulation relative to employment caused the capital-to-output ratio to fall significantly in both Germany and Japan. In France, Holland, and the United States, the capital-to-output ratio declined only

\footnotetext{
${ }^{4}$ Christensen, Cummings and Jorgenson (1980) follow a somewhat different methodology, but find the same basic features of the data as shown in Table 1.
} 
Table 2: Productivity Growth and Capital Deepening (average growth rates)

\begin{tabular}{|c|c|c|c|c|c|c|c|c|c|}
\hline \multirow[b]{2}{*}{ Country } & \multicolumn{3}{|c|}{ TFP } & \multicolumn{3}{|c|}{$\mathrm{K} / \mathrm{L}$} & \multicolumn{3}{|c|}{$\mathrm{K} / \mathrm{Y}$} \\
\hline & $50-60$ & $60-79$ & 79-89 & $50-60$ & $60-79$ & $79-89$ & $50-60$ & $60-79$ & $79-89$ \\
\hline Germany & 4.8 & 1.9 & 0.6 & 4.5 & 6.7 & 3.6 & -2.1 & 2.1 & 1.5 \\
\hline Japan & 4.9 & 2.8 & 1.2 & 1.5 & 10.4 & 5.0 & -4.0 & 3.4 & 1.8 \\
\hline USA & 1.6 & 1.1 & 0.8 & 2.2 & 1.9 & 1.5 & -0.3 & 0.0 & 0.2 \\
\hline France & 2.9 & 2.2 & 1.0 & 3.8 & 6.2 & 4.2 & -0.7 & 1.5 & 1.6 \\
\hline Holland & 2.6 & 2.6 & 0.6 & 3.6 & 4.9 & 2.9 & -0.5 & 0.3 & 1.2 \\
\hline UK & 0.5 & 1.2 & 0.5 & 4.4 & 5.3 & 3.3 & 2.1 & 2.0 & 1.5 \\
\hline
\end{tabular}

Notes: K/L denotes the capital-labor ratio; K/Y denotes the capital-output ratio. Statistics refer to the entire economy. Source: Wolff (1996)

modestly over the 1950s, and in the UK it actually rose.

In the later stage of catch-up, the earlier patterns of TFP growth and capital accumulation are reversed. TFP growth slowed by 3 percentage points in Germany and by 2 percentage points in Japan during this stage, while in other countries it changed little on average. The capital-labor ratio rose sharply in Germany and Japan during this stage.

Our theory emphasizes the role of capital accumulation in response to capital destruction and delayed adoption of new technologies. Arguably, the economic experience of other European countries such as France, Italy and Holland reflects some of the same economic forces during this time period, although to a lesser degree than Germany and Japan. Indeed the data suggest qualitatively similar though more muted patterns of growth and capital accumulation for these countries. Both France and Italy experienced high rates of return on capital combined with relatively modest rates of investment during the early phase of transition. For these countries, the rates of return on capital decline rapidly while the investment shares stay relatively constant over time. France also shows a strikingly similar albeit more muted pattern of growth in total factor productivity and the capital-labor ratio compared to Germany and Japan. As in Germany and Japan, TFP growth in France is initially high but declines over time while the growth rate in the capital-labor ratio is low and rising between the 50-60 and 60-79. 
Figure 1: Manufacturing Sector in Germany
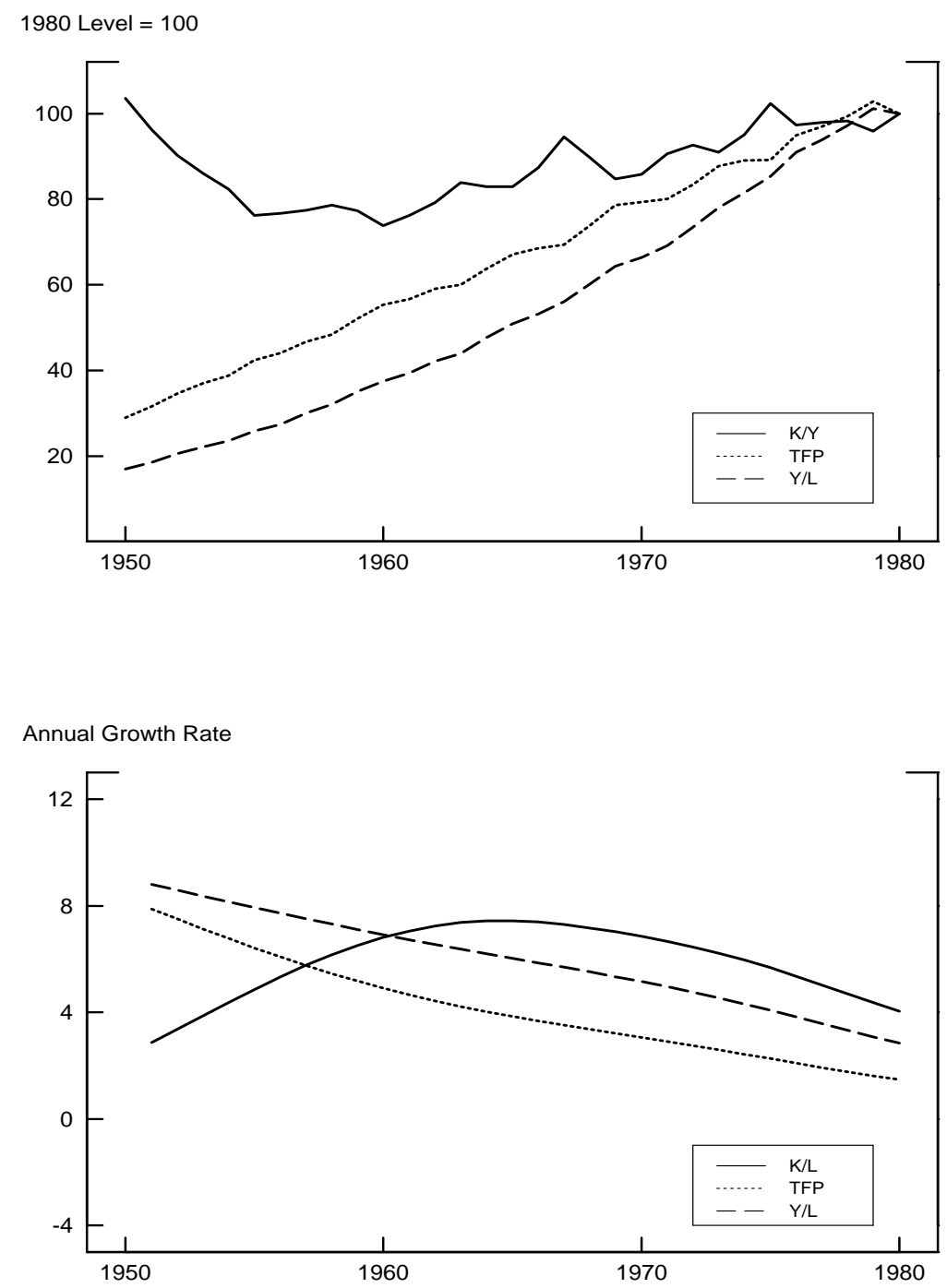

Figures 1 and 2 provide additional graphical evidence for two distinct phases of catch-up for Germany and Japan. ${ }^{5}$ For each country, the upper panel shows the levels of the capital-output ratio $(\mathrm{K} / \mathrm{Y})$, TFP, and output per hour (Y/L) in the manufacturing sector. These series are normalized to 100 in 1980. The lower panel of each figure shows the smoothed growth rates for the capital-labor ratio (K/L), TFP, and output per hour in the manufacturing sector. To reduce the higher frequency fluctuations in the growth rate series, we fit a spline approximation to the level data and compute growth rates from these spline approximations.

\footnotetext{
${ }^{5}$ We thank Bart van Ark and Dirk Pilat, who kindly provided us with their data for these two figures.
} 
Figure 2: Manufacturing Sector in Japan
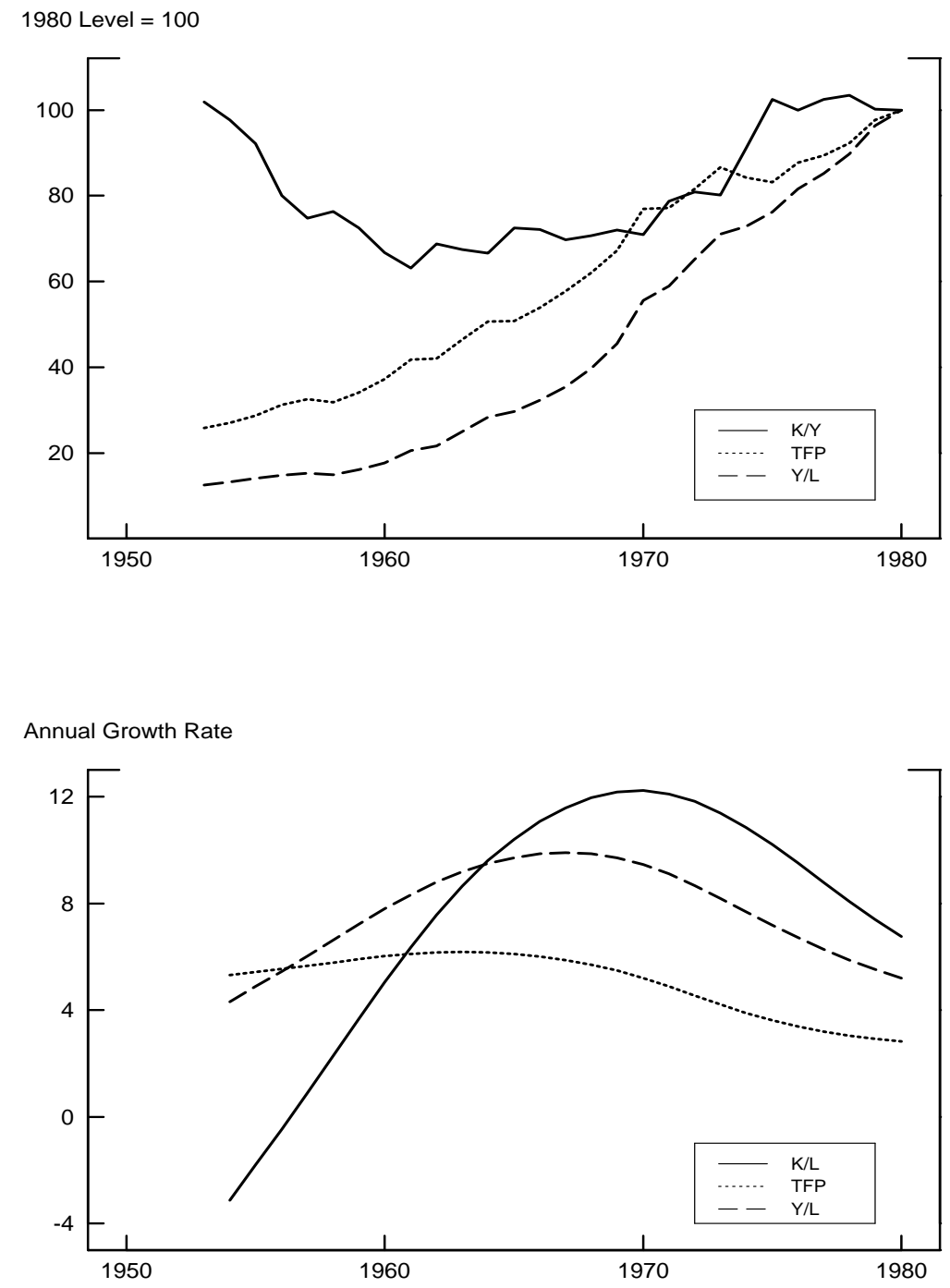

In the early phase of catch-up, German manufacturing experienced high rates of labor and total factor productivity growth, but the capital-output ratio declined reflecting the relatively subdued pace of capital accumulation. This early period lasted for about the decade of the 1950s, over which time the capital-output ratio fell by nearly 30 percent from its 1950 level. Consistent with the economywide data documented in Table 1, productivity growth peaked well in advance of the peak in the rate of growth in the capital-labor ratio. During the later stage, beginning in about 1960, productivity growth in German manufacturing slowed, while the capital-output ratio increased as the pace of capital deepening accelerated. 
The patterns of productivity and capital deepening in Japanese manufacturing are similar to that in Germany. As shown in Figure 2, the decline in the capitaloutput ratio is much more pronounced in Japan and the initial rise in productivity growth rates occurs later than in Germany. Again, the rate of productivity growth peaks well in advance of the peak rate of increase in the capital-labor ratio.

\subsection{Sources of Growth}

A key factor contributing to the low level of productivity in the early postwar period is that Germany and Japan had fallen further behind the technological frontier represented by the United States during the war years. ${ }^{6}$ The technological isolation experienced by Germany and Japan during both the prewar military build-up and the war itself contributed to the slow diffusion of new technologies. Ohkawa and Rosovsky (1968, p.42) summarize the situation in Japan as follows:

The war and its aftermath produced a long interruption of normal Japanese private sector investment, and hence an especially large gap or pool of untapped modern technology. This was further enlarged by the acceleration of productivity growth in industrialized countries generally.

Another factor contributing to Germany and Japan's growth opportunities at the end of the war was the lack of widespread application of mass-production techniques in both countries during the prewar period. Relatedly, the absence of industries producing modern consumer durables on a wide scale afforded additional opportunities for rapid growth in the postwar period. Finally, sectoral transformations yielded productivity gains as both economies shifted away from military-related activities and the agricultural and craft sectors toward private industrial production. ${ }^{7}$

For each of these contributing factors, the adoption of new techniques and the development of new industries required substantial amounts of new investment in

\footnotetext{
${ }^{6}$ German labor productivity fell from 46 percent of the U.S. level in 1938 to only 30 percent in 1950, a 35 percent drop in the level of relative productivity. The percent decline in Japan's relative productivity was of the same magnitude. Germany and Japan did not regain their prewar positions relative to the United States again until around 1960 (Maddison (1991)).

${ }^{7}$ Interestingly, increases in human capital do not appear to have contributed much to Germany and Japan's postwar productivity catch-up relative to the United States (see Denison (1967), Denison and Chung (1976), and Maddison (1995)). Nevertheless, the existence of a well-educated workforce and sizable pools of scientists and engineers in both Germany and Japan was key to those countries' ability to adopt and adapt new production methods and technologies. More generally, following the immediate postwar reconstruction phase, both countries benefitted from legal and institutional structures and monetary regimes that constituted a "social capability" for growth, in the terms of Abramovitz (1995).
} 
plant and equipment. Because they share the characteristic that the productivity improvement is embodied in investment, we lump these different factors together under the general rubric of "embodied technological change."

\section{The Model}

Previous research on the postwar catch-up of Germany and Japan has focussed on production technologies that feature a high degree of substitutability between capital and labor. Putty-clay capital provides an alternative view, in which capitallabor ratios on existing machines are rigid. ${ }^{8}$ As a consequence, in the early stage of catch-up, investment is directed at adding new machines with relatively low capital intensity. As emphasized by Maddison (1964), such "capital widening" expands the employment and output capacity of industry, but dampens the growth rate of capital relative to labor. Over time, the catch-up process switches from one of capital widening to one of capital-deepening, that is, raising the quantity of capital per worker. During this latter stage, capital serves as a substitute for labor in production, and the capital-labor ratio increases rapidly.

We evaluate Germany and Japan's transition dynamics in an optimizing general equilibrium model based on putty-clay technology developed in Gilchrist and Williams (2000). This framework naturally admits a distinction between capital widening and capital deepening - that is, between investment on the extensive and intensive margins - that is entirely absent from the standard putty-putty model. In the putty-clay model, capital goods embody the level of technology and the choice of capital intensity made at the time of their creation. Ex ante, the choice of capital intensity - the amount of capital to be used in conjunction with one unit of labor is based on a standard Cobb-Douglas production function. Ex post, the production function is of the Leontief form with a zero-one utilization decision. Over time, as the leading-edge technology improves, older, less efficient vintages of capital become too costly to operate and are scrapped.

\footnotetext{
${ }^{8}$ The putty-clay model was originally introduced by Johansen (1959). For further references to the putty-clay literature and a more detailed description of the model described below, see Gilchrist and Williams (2000).
} 


\subsection{The Production Technology}

Each period a set of new investment "projects" becomes available. Constant returns to scale implies an indeterminacy of scale at the level of projects, so without loss of generality, we normalize all projects to employ one unit of labor at full capacity. We refer to these projects as "machines." The productive efficiency of a machine initiated at time $t$ is affected by four terms: the economywide level of disembodied technology $A_{t}$, the economywide level of vintage technology, $\theta_{t}$, an idiosyncratic shock to productivity, $\mu_{t}$, and the amount of capital invested per machine, $k_{t}$. We assume that capital goods require one period for initial installation and fail at the exogenous rate $\delta$.

The economywide levels of disembodied and vintage (embodied) technologies follow stochastic processes described in the next section. We assume that the trend level of embodied technology increases over time with gross growth rate $(1+g)^{1-\alpha}$, while disembodied technology has no trending component. ${ }^{9}$ The idiosyncratic shock $\mu_{t}>0$ is drawn from a log-normal distribution

$$
\log \mu_{t} \sim N\left(-\frac{1}{2} \sigma^{2}, \sigma^{2}\right)
$$

where the mean correction term $-\frac{1}{2} \sigma^{2}$ implies $E\left(\mu_{t}\right)=1$. The realized level of combined vintage and idiosyncratic efficiency $\mu_{t} \theta_{t}$ is assumed to be permanent and thus embodied in the machine.

Final-goods output produced at time $t$ by a machine built in period $t-j$ with embodied technology $\mu_{t-j} \theta_{t-j}$ and capital $k_{t-j}$ is given by

$$
Y_{t}\left(\mu_{t-j} \theta_{t-j} k_{t-j}^{\alpha}\right)=A_{t} 1\left\{L_{t}\left(\mu_{t-j} \theta_{t-j} k_{t-j}^{\alpha}\right)=1\right\} \mu_{t-j} \theta_{t-j} k_{t-j}^{\alpha},
$$

where $L_{t}\left(\mu_{t-j} \theta_{t-j} k_{t-j}^{\alpha}\right)$ is labor employed at the machine and the zero-one indicator function $1\left\{L_{t}\left(\mu_{t-j} \theta_{t-j} k_{t-j}^{\alpha}\right)=1\right\}$ reflects the Leontief nature of machine production with unit labor capacity. Let

$$
X_{t} \equiv \mu_{t} \theta_{t} k_{t}^{\alpha}
$$

denote the efficiency level of a particular machine, and let $\bar{X}_{t}=\theta_{t} k_{t}^{\alpha}$ denote the mean efficiency of such machines. To characterize the production possibilities of this economy, we note that, once produced, machines are distinguished only by their efficiency level $X$. Let $H_{t}(X)$ denote the quantity of machines of efficiency

\footnotetext{
${ }^{9}$ This distinction between the underlying sources of trend productivity growth is of no consequence for the analysis in this paper.
} 
level $X$ that are available for use at time $t$. Integrating over $X$ yields expressions for aggregate output

$$
Y_{t}=A_{t} \int_{0}^{\infty} 1\left\{L_{t}(X)=1\right\} X H_{t}(X) d X
$$

and aggregate labor input

$$
L_{t}=\int_{0}^{\infty} L_{t}(X) H_{t}(X) d X
$$

The quantity of machines with efficiency $X$ available for production at time $t+1$ equals the quantity of machines that survive from period $t$ plus the quantity of new machines with efficiency $X$ that are put into place at time $t$. The lognormal distribution for $\mu_{t}$ implies that $X_{t}$ is also log-normally distributed with $E\left(\log X_{t} \mid \bar{X}_{t}\right)=\log \bar{X}_{t}-\frac{1}{2} \sigma^{2}$. Hence, the quantity of machines of a given efficiency $X$ evolves according to

$$
H_{t+1}(X)=(1-\delta) H_{t}(X)+(\sigma X)^{-1} \phi\left(\frac{1}{\sigma}\left(\log X-\log \bar{X}_{t}+\frac{1}{2} \sigma^{2}\right)\right) Q_{t}
$$

where $\phi()$ is the standard normal probability distribution function and $Q_{t}$ is the aggregate quantity of new machines that are put in place at time $t$. The term $(\sigma X)^{-1} \phi\left(\frac{1}{\sigma}\left(\log X-\log \bar{X}_{t}+\frac{1}{2} \sigma^{2}\right)\right)$ thus is the density of new machines with efficiency level $X$.

In the absence of government spending or other uses of output, aggregate consumption, $C_{t}$, satisfies

$$
C_{t}=Y_{t}-k_{t} Q_{t}
$$

where $k_{t} Q_{t}$ equals aggregate investment expenditures. ${ }^{10}$

Preferences of the representative household are given by

$$
\frac{1}{1-\gamma} E_{t} \sum_{s=0}^{\infty} N_{t+s} \beta^{s}\left(\frac{C_{t+s}\left(N_{t+s}-L_{t+s}\right)^{\zeta}}{N_{t+s}}\right)^{1-\gamma}
$$

where $0<\beta<1, \gamma>0$, and $\zeta>0$. The labor endowment, $N_{t}$, is assumed to grow at a constant rate $n, N_{t}=N_{0}(1+n)^{t}$. The social planner chooses contingency plans for factor utilization, $\left\{L_{t}(X), \forall X>0\right\}$, and investment decisions, $\left\{k_{t}, Q_{t}\right\}$, to maximize welfare subject to the labor endowment and equations $2-6$. The information set at

\footnotetext{
${ }^{10} \mathrm{We}$ abstract from international trade. In principle, the process of catch-up can be accelerated by borrowing from abroad. For Germany and Japan, the trade balance tended to be roughly in balance on average over the 1950s and 1960s, suggesting that the closed-economy assumption is not a bad approximation for the purposes of this paper.
} 
time $t$ includes the current and past levels of economywide disembodied technology, $A_{t}$, and embodied technology, $\theta_{t}$. However, the idiosyncratic shock to individual machines $\mu_{t}$ is revealed only after period $t$ allocations are made.

\subsection{The Utilization and Investment Decisions}

Each period the social planner chooses which machines to utilize and which machines to leave idle. Given the Leontief structure of production and the assumption of no machine startup or shutdown costs, this decision problem is static in nature and is equivalent to the choice of a cutoff value, $W_{t}$, whereby machines with productivity $A_{t} X \geq W_{t}$ are run at capacity, while those less productive are left idle. Let

$$
z_{t}^{s} \equiv \frac{1}{\sigma}\left(\log W_{t}-\log A_{t} \bar{X}_{s}+\frac{1}{2} \sigma^{2}\right)
$$

measure the productivity difference between the efficiency of the marginal machine in use at time $t$ and the mean efficiency of a vintage $s$ machine.

Capacity utilization of the set of vintage $s$ machines at time $t$ - the ratio of actual output produced by all vintage $s$ machines to the amount of output that would be produced if all such machines were operated at full capacity - is given by $\left(1-\Phi\left(z_{t}^{s}-\sigma\right)\right)$, where $\Phi(\cdot)$ denotes the standard normal cumulative distribution function. Equation 3 then implies that aggregate output may be expressed as a function of current capacity utilization rates and past investment decisions

$$
\begin{aligned}
Y_{t} & =A_{t} \int_{A_{t} X>W_{t}}^{\infty} X H_{t}(X) d X \\
& =\sum_{j=1}^{\infty}\left(1-\Phi\left(z_{t}^{t-j}-\sigma\right)\right)(1-\delta)^{j} Q_{t-j} A_{t} \bar{X}_{t-j} .
\end{aligned}
$$

Similarly, aggregate labor may be expressed as

$$
\begin{aligned}
L_{t} & =\int_{X>W_{t}}^{\infty} H_{t}(X) d X \\
& =\sum_{j=1}^{\infty}\left(1-\Phi\left(z_{t}^{t-j}\right)\right)(1-\delta)^{j} Q_{t-j}
\end{aligned}
$$

where $1-\Phi\left(z_{t}^{s}\right)=\operatorname{Pr}\left(A_{t} X_{s}>W_{t} \mid A_{t}, W_{t}\right)$ is the share of vintage $s$ machines in use at time $t$.

The social planner's problem may now be restated in terms of the choices of the cutoff, $W_{t}$, the capital intensity for new machines, $k_{t}$, and the number of new machines, $Q_{t}$, produced at time $t$. Formally, the social planner chooses contingency 
plans for the sequence $\left\{W_{t+s}, k_{t+s}, Q_{t+s}\right\}_{s=0}^{\infty}$ to maximize equation 7 given the stock of existing machines and the labor endowment, and subject to equations 2, 5, 6, 8, 9 , and 10 .

Let $U_{c, t+s}$ denote the marginal utility of consumption and $U_{L, t}$ denote the marginal utility associated with an incremental increase in work (decrease in leisure). The optimal cutoff $W_{t}$ satisfies

$$
U_{c, t} W_{t}+U_{L, t}=0
$$

The optimal choice of capital intensity, $k_{t}$, satisfies the condition

$$
U_{c, t}=E_{t}\left\{\sum_{j=1}^{\infty} \beta^{j}(1-\delta)^{j} U_{c, t+j}\left(1-\Phi\left(z_{t+j}^{t}-\sigma\right)\right)\right\}\left(\alpha \frac{A_{t+j} \bar{X}_{t}}{k_{t}}\right) .
$$

The final term in the right-hand side of this expression equals the marginal gain to production associated with an incremental increase in $k_{t}$, taking into account expected future rates of capital utilization implied by equation $11 .{ }^{11}$ Similarly, the optimal quantity of new machines, $Q_{t}$, satisfies

$U_{c, t} k_{t}=E_{t}\left\{\sum_{j=1}^{\infty} \beta^{j}(1-\delta)^{j}\left(U_{C, t+j}\left(1-\Phi\left(z_{t+j}^{t}-\sigma\right) A_{t+j} \bar{X}_{t}-U_{L, t+j}\left(1-\Phi\left(z_{t+j}^{t}\right)\right)\right)\right\}\right.$.

The left-hand side of this expression equals the forgone utility associated with producing a new machine with capital intensity $k_{t}$. The right-hand side of this expression equals the incremental gain in the present discounted value of the future utility associated with the additional output from such a machine less the disutility of labor associated with operating such a machine.

We calibrate the model using standard parameter values from the literature (e.g., Kydland and Prescott (1991) and Christiano and Eichenbaum (1992)). Each period in the model corresponds to one year. The calibrated parameters are $\beta=0.97, \gamma=$ $2, \zeta=3, g=0.024, n=0.01, \delta=0.1, \alpha=0.36$. Trend growth in labor is chosen to match the German and Japanese postwar data; trend productivity growth is set equal to its average rate in the United States over 1950-80. The results reported in

\footnotetext{
${ }^{11}$ An increase in $k$ has a direct effect on output through its effect on $\bar{X}_{s}$. It also potentially has an indirect effect through utilization rates - a higher $k$ implies increased utilization. The marginal utility associated with the least efficient machine is, however, zero; that is,

$$
\frac{1}{\sigma} \phi\left(z_{t}^{s}-\sigma\right) \bar{X}_{s}-\frac{1}{\sigma} \phi\left(z_{t}^{s}\right) W_{t}=0
$$
}

and hence the indirect effect vanishes at the optimum. 
this paper are not sensitive to reasonable variations in these parameters. Following Gilchrist and Williams (2000), we set $\sigma=0.15$ in the putty-clay model.

\section{Model Experiments}

In this section, we examine the transition dynamics of the putty-clay model in response to destruction of the capital stock and to the availability of new, more productive technologies. We start by considering the effects of capital destruction. This experiment highlights the importance of putty-clay capital in explaining key aspects of labor and capital transition dynamics. In the next two experiments, we consider increases in disembodied and embodied technology. Finally, the fourth experiment combines both capital destruction and increases in embodied technology in an empirically plausible manner, and evaluates the model's ability to match features of Germany and Japan's postwar experiences along a number of dimensions.

\subsection{Capital Destruction}

We begin our model experiments by considering the effects of destroying 20 percent of the capital stock. ${ }^{12}$ The magnitude of the simulated shock is roughly consistent with estimates of the effects of war-related destruction and population inflows, as discussed in section 2. The results from this experiment are shown in Figure 3, which plots the dynamic responses of the percent deviations of labor, output, and the capital-output ratio from their respective steady-state values. The upper panel shows the response for the putty-clay model, while the lower panel shows the response for the Solow putty-putty model, which allows ex post capital-labor substitutibility but is otherwise identical to the putty-clay model described above. ${ }^{13}$

In the putty-clay model, capital destruction has an immediate large negative effect on employment and output, owing to the short-run complementarity between capital and labor implied by the Leontief nature of production. Employment initially falls by 15 percent and output falls by 17 percent. Along the transition path, output, capital, and employment all rise monotonically. The capital-output ratio exhibits a U-shaped response: After a small initial drop, the capital-output ratio declines for several years before gradually returning to its steady-state value.

\footnotetext{
${ }^{12}$ We simulate the model using an extended path algorithm based on Fair and Taylor (1983). For the simulations, we truncate the maximum lifespan of machines at 45 years.

${ }^{13}$ Gilchrist and Williams (2000), section 2.e, provide a full specification of the Solow putty-putty model.
} 
Figure 3: Destruction of 20 Percent of the Capital Stock

Putty-Clay Model

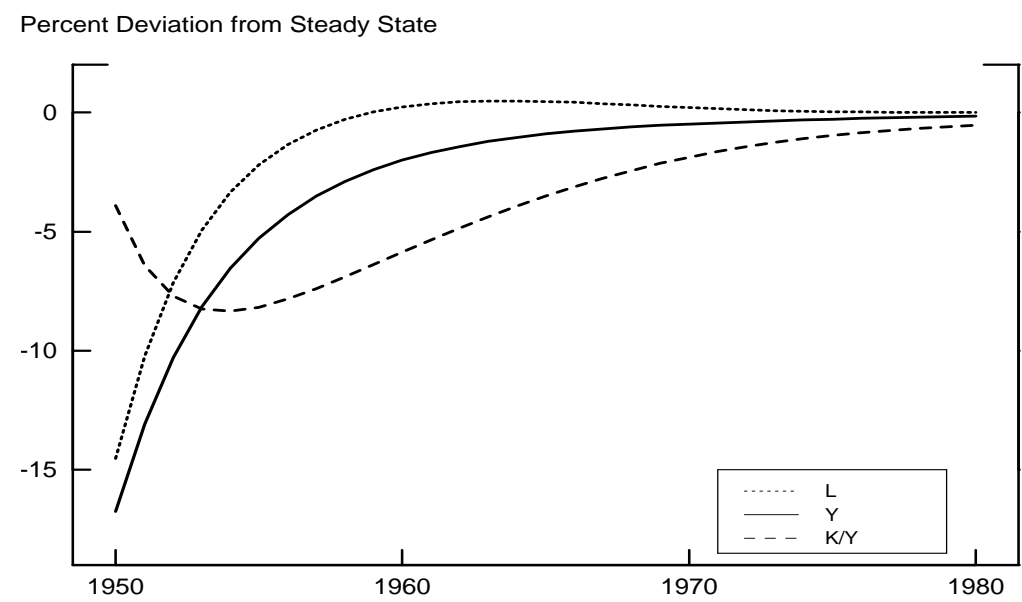

Solow Model

Percent Deviation from Steady State

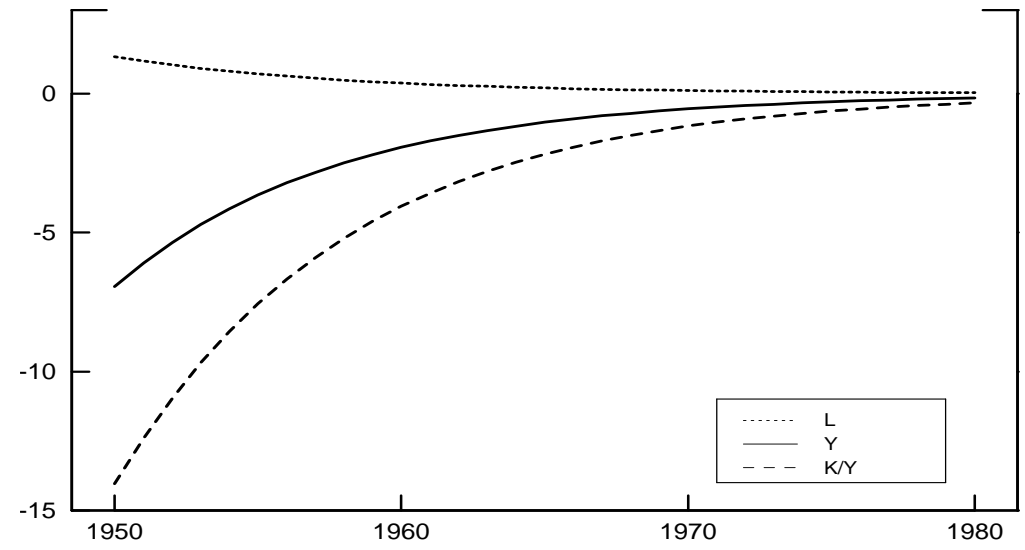

In the Solow putty-putty model, employment actually rises in response to the destruction in capital. As a result, the initial drop in output is 7 percent - less than half as large as in the putty-clay model. This decline in output roughly equals the product of the capital share times the amount of capital destroyed. The modest rise in employment occurs because the high rate of return on savings offsets the low marginal product of labor. Along the transition path, employment gradually falls while output and the capital stock rise. After a sharp initial drop of 14 percent, the capital-output ratio rises monotonically back to its steady-state value.

The two models imply very different transition dynamics for employment and the 
Figure 4: Putty-Clay Investment Dynamics Following Capital Destruction

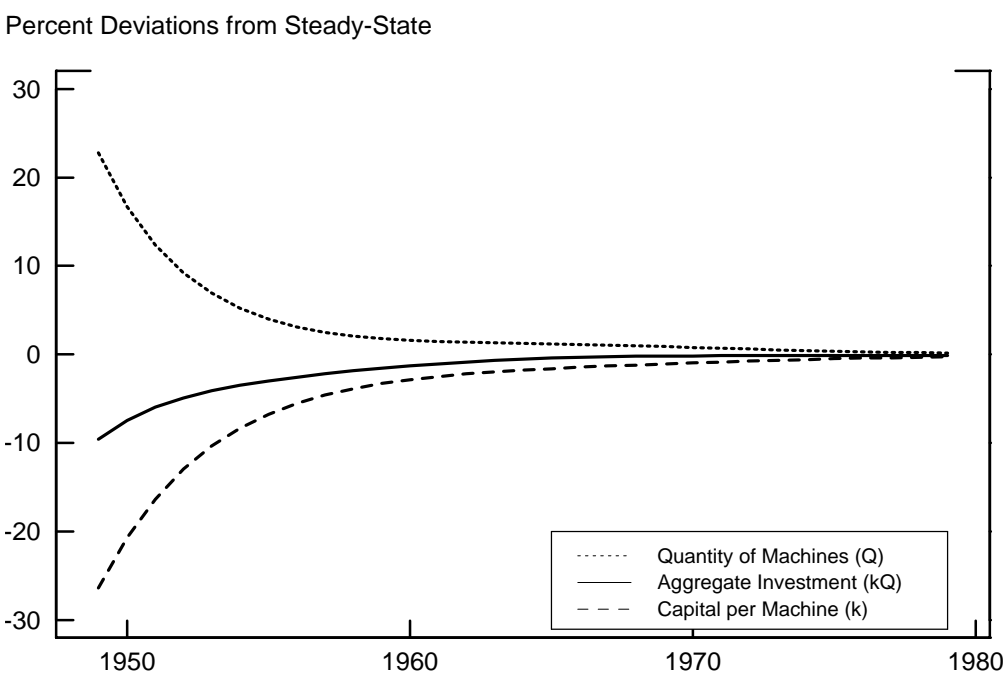

capital-output ratio, with the predictions of the putty-clay model more consistent with the data along these dimensions. Figure 4 decomposes the response of aggregate investment in the putty-clay model into capital per machine and the quantity of new machines. Investment along the extensive margin (machine quantity) increases sharply, reflecting the process of capital widening. Given this rapid pace of machine creation, if the capital-labor ratio of new machines were to remain constant, the implied rate of investment would be very high. Such high rates of investment would entail either a sharp rise in the marginal cost of production or a large reduction in consumption. By reducing capital per machine, productive capacity is quickly restored while investment rates are kept low, as seen in the figure. With additions to capacity, investment along the intensive margin increases and capital per machine gradually returns to its steady-state level. This initial phase of capital widening followed by one of capital deepening underlies the U-shaped response of the capitaloutput ratio in the putty-clay model.

\subsection{An Increase in Disembodied Technology}

Although capital destruction alone can explain some of the features in the German and Japanese data, it cannot account for the magnitude of the decline in the capitaloutput ratio or the patterns in productivity growth experienced by Germany and Japan during the postwar period. To explain these phenomena, we now consider transition dynamics in response to permanent increases in technology. We begin by 
Figure 5: Immediate Increase in Disembodied Technology
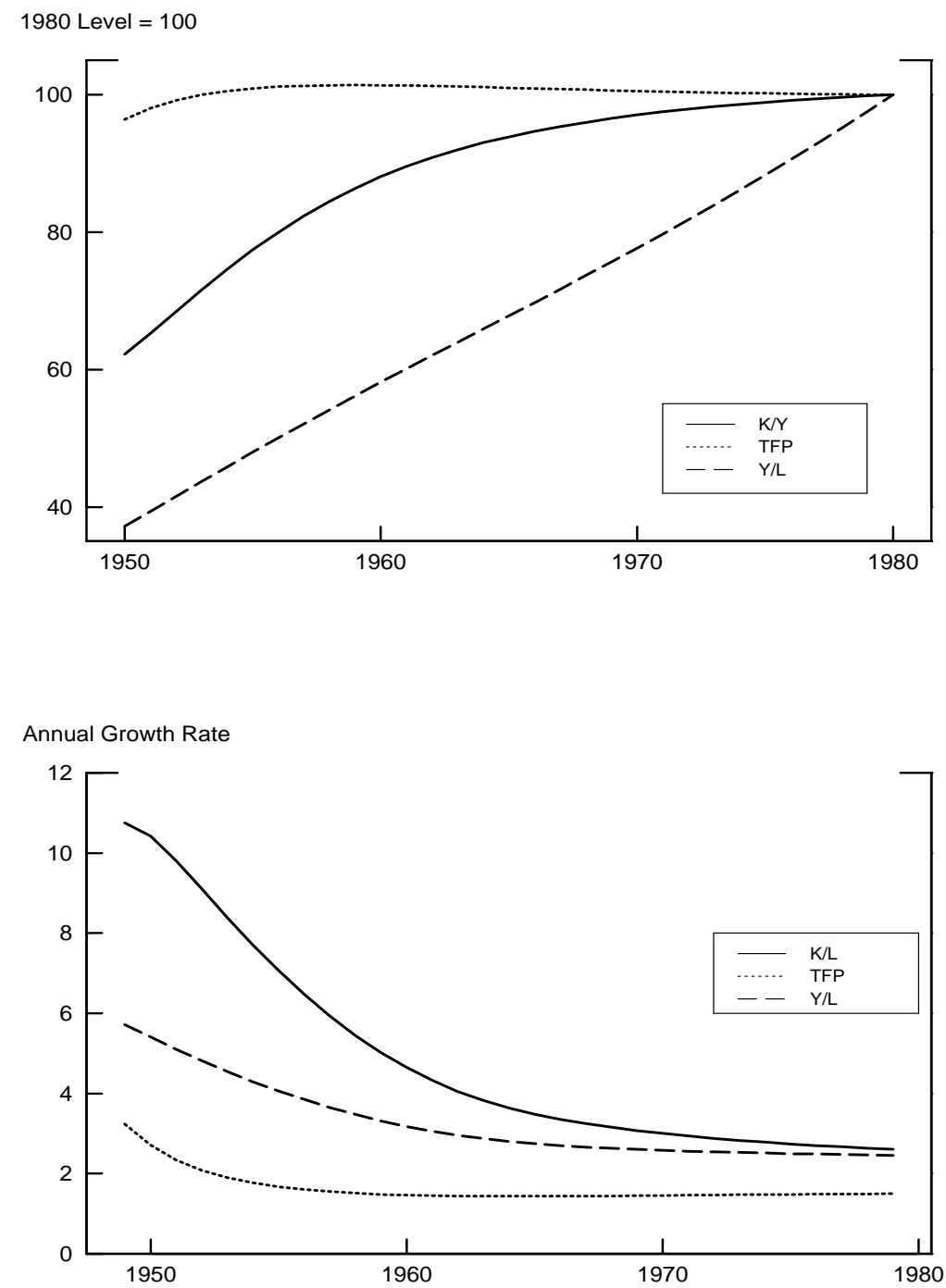

considering the effect of an increase in disembodied technology for the putty-clay model. ${ }^{14}$

Figure 5 shows the transition dynamics following an immediate permanent rise in the level of disembodied technology. The upper panel of the figure reports the levels of the capital-output ratio, TFP, and labor productivity; the lower panel shows the growth rates of the capital-labor ratio, TFP, and labor productivity. These variables correspond to the data plotted in Figures 1 and 2. In the exercises reported in the

\footnotetext{
${ }^{14}$ Because production possibilities are immediately expanded in response to disembodied technological change, the relative fixity of factor proportions has little effect on transition dynamics in this experiment, and we obtain very similar results with the Solow putty-putty model.
} 
remainder of the paper, the magnitude of the productivity shock is calibrated to roughly match the degree of catch-up in economywide TFP for Germany relative to the United States achieved by 1980.

The transition dynamics implied by a one-time increase in disembodied technological change are clearly at odds with the data for Germany and Japan. This shock generates a monotonically increasing capital-output ratio and virtually no growth in total-factor productivity following the initial increase. ${ }^{15}$ In addition, the growth rate in the capital-labor ratio declines monotonically over time, in contrast to the hump-shaped pattern observed in the data.

\subsection{An Increase in Embodied Technology}

The transition dynamics implied by an immediate increase in embodied technology provide a much better fit to the historical data than do those implied by an immediate increase in disembodied technology. Figure 6 reports the effects of an immediate permanent rise in $\theta_{t}$ - the mean level of technology determining the productivity of new machines - in the putty-clay model. ${ }^{16}$

The productivity gains associated with an increase in embodied technology occur only as the leading-edge technology is incorporated in the existing capital stock. As in the case of capital destruction, investment is limited by rapidly rising marginal costs of production in the short run. As a result, the initial expansion of output, hours, and investment is muted. This gradual adoption of new technology through investment explains the high but declining growth rates of total-factor and labor productivity. ${ }^{17}$

An increase in embodied technology also provides a natural explanation for the

\footnotetext{
${ }^{15}$ We compute TFP as a Solow residual from the Cobb-Douglas production function where the "capital stock" is calculated according to the standard perpetual inventory method. Because the putty-clay model deviates from both of these assumptions, this measure of TFP differs from the true level of disembodied technology. The relatively small variation in measured TFP growth shown in the figure is a result of this mismeasurement.

${ }^{16}$ Qualitatively, the results from this experiment are similar to those in a putty-putty model. Quantitatively, the putty-putty model implies a stronger comovement between productivity and capital deepening that is less compatible with the empirical evidence.

${ }^{17}$ If the capital stock were measured in efficiency units, all the productivity gains resulting from an increase in embodied technology would be ascribed to capital accumulation rather than TFP. Throughout this paper, we assume that changes in embodied technology are not reflected in the data for investment and capital stocks. We believe this approach is appropriate for comparisons of simulated to actual data. Greenwood, Hercowitz and Krusell (1997) argue that the U.S. data in the postwar period incorporate only a fraction of the improvements in embodied technology. The national accounts of Germany and Japan are computed in a similar fashion.
} 
Figure 6: Immediate Increase in Embodied Technology
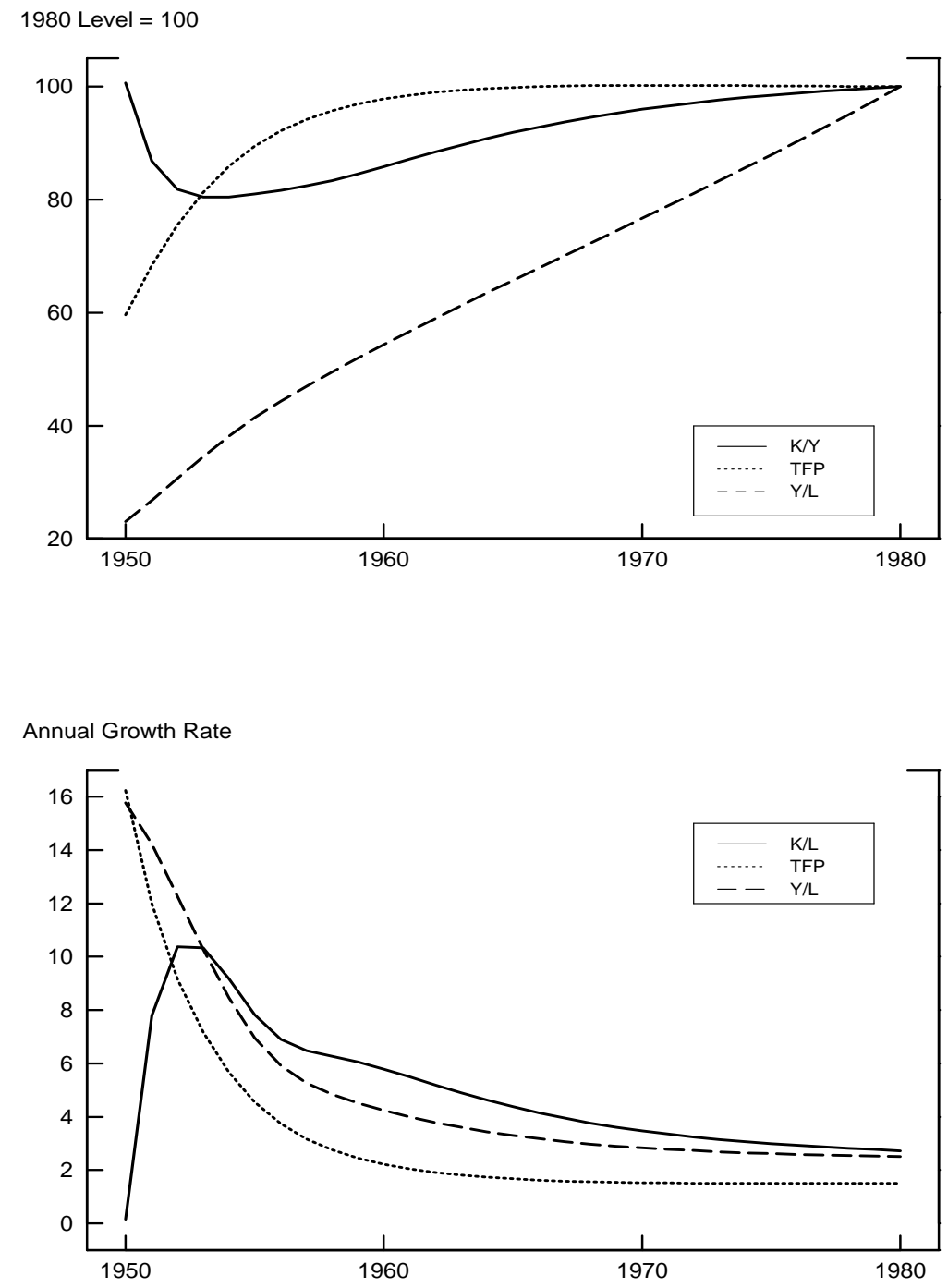

U-shaped response of the capital-output ratio. Because there is no direct effect of the increase in technology on measured productivity, neither output nor capital shows much response in the initial period. The initial phase of the expansion is then characterized by a period of capital widening as productive capacity is increased at low cost. This period of declining capital-output ratios lasts for several years, after which the economy begins the process of capital deepening. During this latter phase, the capital-output ratio rises monotonically as the economy converges to the new steady state.

The process of capital widening followed by capital deepening also explains the 
hump-shaped response of the growth rate in the capital-labor ratio observed in the data. With the rapid expansion in machine quantity, labor is growing nearly as rapidly as capital. As productive capacity is established, the growth rate of the capital-labor ratio increases. This growth rate peaks a few years after the start of the transition. During the capital-deepening phase, the growth rate of the capitallabor ratio remains above its steady-state rate but declines monotonically over time.

\subsection{A Rapid Phase-In of Embodied Technology}

The preceding simulations suggest that both capital destruction and embodied technological change are key elements in explaining the transition dynamics of post-war Germany and Japan. In this section we consider the combined implications of capital destruction and technological change. In the previous experiment, the access to new technology was assumed to be immediate, with only the forces of capital accumulation slowing it down. Such an assumption is most likely too stark a description of how rapidly new technologies can be adopted however. Arguably, it takes some time for producers to identify and purchase new capital goods and put into place production processes that are most appropriate for their industry. Accordingly, we also make allowance for some delay in Germany and Japan's obtaining complete access to the leading-edge technology associated with new capital goods. We still abstract from other features of the economy, habit formation or subsistence levels of consumption and investment adjustment costs, which may further slow investment and the transition to the new steady state. ${ }^{18}$ Such delay mechanisms would have similar implications for model dynamics as our assumption of a rapid phase-in of the new technology.

We model the rapid phase-in of technology as a series of anticipated increases in $\theta_{t}$, where the ultimate increase in the level of embodied technology is the same as in the preceding experiment. Our goal in this exercise is to emphasize the process of capital accumulation rather than diffusion as the primary driving force behind the catch-up process. Accordingly, we assume that the technology diffuses quickly. Specifically, the increase in the level of embodied technology is assumed to be (1-

\footnotetext{
${ }^{18}$ See for example, Alvarez (2004), who considers the role of habit formation in slowing investment following a capital-destruction shock. Similarly, preferences may include a subsistence level of consumption which, particularly in the case of Japan, would imply more gradual capital accumulation early in the transition (Christiano 1989). Moreover, capital market imperfections and adjustment costs may have reduced investment growth relative to the optimal amount described in the simulations.
} 
Figure 7: Phased-in Increase in Embodied Technology with 20\% Capital Destruction
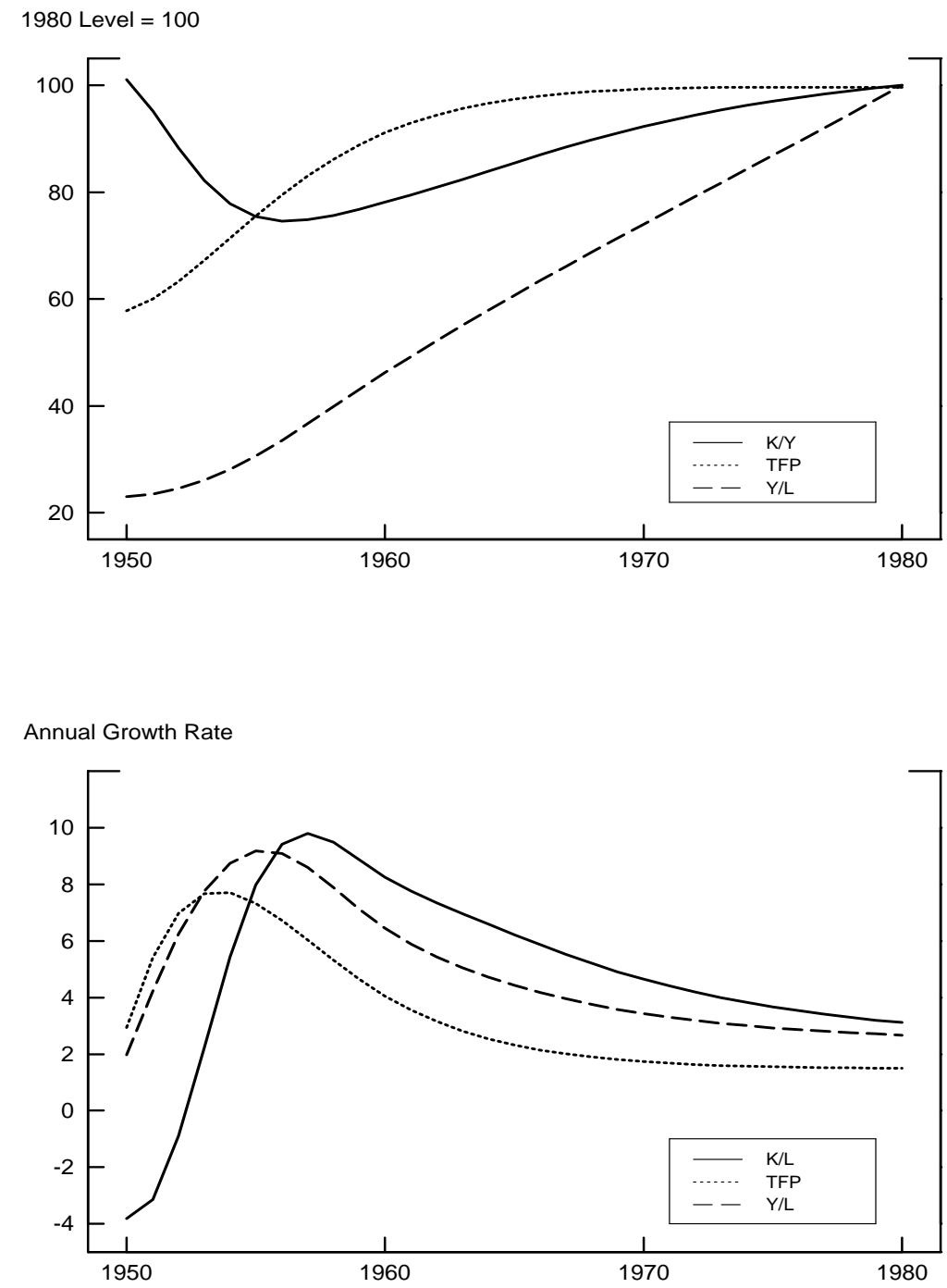

$\left.0.75^{t}\right)$ in period $t$, which implies that 25 percent of the ultimate rise in $\theta$ occurs within one year, and 75 percent within five years. We further assume that the economy starts with a capital stock that is 20 percent below its steady-state level. The transition dynamics for the combined simulation are plotted in Figure 7.

The rapid phase-in of embodied technology provides an incentive to delay investment in the first few years of the transition process in order to take advantage of additional improvements in technology yet to come. In addition to delaying the investment process, the rapid phase-in implies that productivity growth rates are initially low and rising, peaking several years out. This pattern reflects both the 
direct effect of the path of technology and the indirect effect of delayed capital expenditures relative to the case of an immediate increase in technology.

The U-shaped response of the capital-output ratio in the model is now more pronounced and provides a close match to those observed in the data. In terms of growth rates, we again observe a hump-shaped response of the capital-labor growth rate. Initially, labor is growing even more rapidly than capital. The peak response of the capital-labor growth rate occurs a few years after the peak response in productivity, a finding that again is in broad agreement with the data.

\subsection{Rates of Return, Investment, and Employment}

The rapid phase-in of embodied technology combined with capital destruction captures the major features of capital and productivity dynamics during Germany and Japan's postwar transition. We now focus on the dynamic responses of the rate of return to capital, investment, and employment. Overall, the model succeeds at resolving the puzzling issue as to why employment, investment, and rates of return were relatively low in the early stages of transition, despite the tremendous growth opportunities that these countries faced at the time.

With the rapid phase-in of embodied technology, real rates of return are plausible and not inconsistent with the relatively high realized rates of return on equity in Germany and Japan during the post-war period. Table 3 compares the model's implications for the real return to capital to the actual data. We consider the effects of the combined experiment of capital destruction and embodied technological change, with and without a rapid phase-in of technology. Without a phase-in of embodied technology, the rate of return averages 36 percent over the first five years, somewhat above the recorded levels. This initial spike in rates of return reflects the large investment opportunities available at the start of the transition. Although substantially lower than the 500 percent rate of return obtained by King and Rebelo (1993) in their study of transition dynamics applied to Germany and Japan, such returns are somewhat high relative to actual returns during this period. With a phase-in of the shock, the simulated rate of return averages 12 percent over the first half of the 1950s, and then rises to 22 percent during the second half of the decade. The rate of return to capital then gradually converges to its long-run value of about 8 percent.

The combination of capital destruction and an increase in embodied technology 
Table 3: Rates of Return and Investment Share

(average annual rates)

\begin{tabular}{lrrrrrrrr}
\hline \hline & \multicolumn{3}{c}{ Rate of Return } & & \multicolumn{3}{c}{ Investment Share } \\
\cline { 2 - 3 } \cline { 7 - 9 } & $50-54$ & $55-59$ & $60-69$ & & $50-54$ & $55-59$ & $60-69$ \\
\hline $\begin{array}{l}\text { Simulated data } \\
\text { Immediate }\end{array}$ & 36 & 17 & 11 & & 4 & 2 & 1 \\
Phased-in & 12 & 22 & 14 & & -2 & 2 & 1 \\
Actual data & & & & & & & \\
Germany & 23 & 27 & 4 & & -3 & -0 & 1 \\
Japan & 28 & 28 & 9 & & -7 & -5 & 1 \\
\hline
\end{tabular}

Notes: Investment share reported as difference from 1980 value.

For sources, see Table 1.

causes the investment share initially to drop, but then rise steadily over most of the 1950s. Loss of capacity combined with some delayed access to frontier technologies dampens investment for several years. The simulated and actual investment shares, reported as differences from their respective 1980 levels, are shown in Table 3. With an immediate increase in the level of embodied technology, the investment share initially rises four percentage points above its 1980 level and remains elevated at that level for several years. In contrast, with the phased-in shock, the simulated investment share in 1950 is about 6 percentage points below its 1980 level. By comparison, Germany's 1950 investment share was about 3-1/2 percentage points below its 1980 level and Japan's 1953 investment share (the first year for which we have data) was about 8 percentage points below its 1980 level. The model predicts a relatively rapid return of the investment share to its steady-state level by 1953, followed by modestly high rates of investment. A similar pattern is seen in the German data, where the investment share reached its 1980 level by 1955 and surpassed it slightly for a number of years thereafter. The investment share in Japan, however, continued to increased markedly in the 1960s.

Finally, the model predicts a sharp rise in employment during the 1950s. Figure 8 plots detrended employment for Germany and Japan, along with employment implied by the model simulation. ${ }^{19}$ The employment patterns for Germany and

\footnotetext{
${ }^{19}$ To detrend employment, we first estimate a log-linear trend over the period 1965-1990. We then extrapolate this trend backwards and subtract it from the full sample of data, starting in 1950. This procedure allows us to capture labor movements associated with transition dynamics rather
} 
Figure 8: Detrended Employment

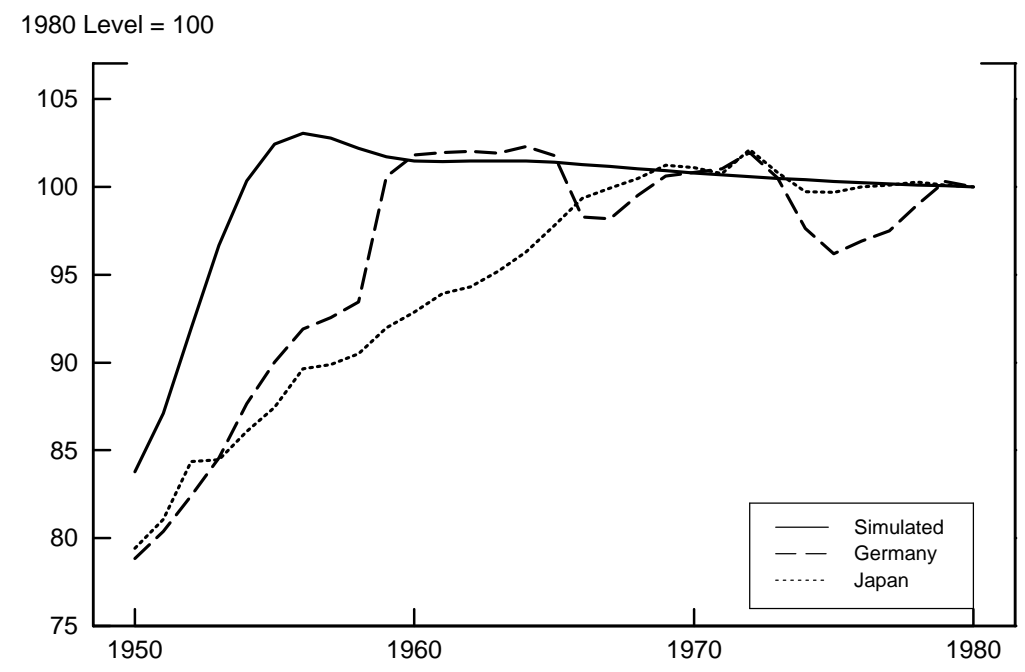

Japan are remarkably similar - employment starts 20 percent below trend and rises monotonically throughout the 1950s, with Germany reaching its trend level somewhat more rapidly than Japan. In the model simulation, employment begins 16 percent below trend and rises monotonically over most of the decade. Although the model's employment dynamics are more rapid than those apparent in the data, the model succeeds in matching the magnitude of the employment response, which is governed by the putty-clay features of the model.

\section{Conclusion}

In this paper we consider a neoclassical interpretation of the postwar growth experiences of Germany and Japan. Unlike research that has focussed exclusively on the role of capital accumulation in a standard growth model, we emphasize the importance of the gap in the level of technology embodied in capital goods and its effect on capital accumulation and productivity growth. In the postwar period, Germany and Japan regained access to advanced technologies embodied in capital goods available from the United States and elsewhere. According to this view, Germany and Japan's "economic miracles" reflected a closing of the gap in "machines." This process was slowed by the putty-clay nature of capital, which necessitated an early stage of capital widening to expand productive capacity before capital deepening could

than more general demographic forces and trends in participation rates that are relevant in the full sample period. 
fully take place. In the putty-clay model, an empirically plausible combination of capital destruction and increases in embodied technology can explain the patterns of productivity, capital accumulation, employment, and rates of return to capital during Germany and Japan's postwar transition.

Germany and Japan's postwar growth experiences provide prime examples of economic transitions determined by embodied technology and putty-clay capital. The postwar patterns of productivity and capital accumulation in Italy, and to a lesser extent, France, share similar qualities with those of Germany and Japan, although the scale of the transition is smaller. These factors are also likely to have been key influences on transitions in post-communist and other newly industrializing countries. Finally, embodied technological change is an important source of growth in the United States and a key ingredient in the U.S. productivity acceleration in the late 1990s. ${ }^{20}$ This paper contributes to our understanding of the medium-run dynamics that we should expect from such growth opportunities.

\footnotetext{
${ }^{20}$ See, for example, Greenwood et al. (1997), Oliner and Sichel (2000), and Greenwood and Jovanovic (2001)).
} 


\section{References}

Abramovitz, Moses, "The Elements of Social Capability," in Bon Ho Koo and Dwight H. Perkins, eds., Social Capability and Long-Term Economic Growth, New York: St. Martin's Press, 1995, chapter 3, pp. 19-47.

Alvarez, Francisco, "Growth Outside the Stable Path: Lessons from the Eurpoean Reconstruction Process," 2004. manuscript, University of Washington Economics Department.

Christensen, Laurits R., Dianne Cummings, and Dale W. Jorgenson, "Economic Growth, 1947-1973: An International Comparison," in J. W. Kendrick and B. Vaccara, eds., New Deveolpments in Productivity Measurement and Analysis, Chicago: University of Chicago Press, 1980.

__ _ _ and _ _ _ "Relative Productivity Levels, 1947-1973," European Economic Review, 1981, 16, 61-94.

Christiano, Lawrence J., "Understanding Japan's Saving Rate: The Reconstruction Hypothesis," Federal Reserve Bank of Minneapolis Quarterly Review, 1989.

and Martin Eichenbaum, "Current Real-Business-Cycle Theories and Aggregate Labor-Market Fluctuations," American Economic Review, June 1992, $82(3), 430-450$.

Cohen, Jerome B., Japan's Postwar Economy, Bloomington: Indiana University Press, 1958.

Denison, Edward F., Why Growth Rates Differ, Washington, DC: Brookings Institution, 1967.

and William K. Chung, How Japan's Economy Grew So Fast: The Sources of Postwar Expansion, Oxford: Oxford University Press, 1976.

Dimson, Elroy, Paul Marsh, and Mike Staunton, Triumph of the Optimists: 101 Years of Global Investment Returns, Princeton, NJ: Princeton University Press, 2002.

Eaton, Jonathan and Samuel Kortum, "Engines of Growth: Domestic and Foreign Sources of Innovation," Japan and the World Economy, 1997, 9, 235259.

Fair, Ray C. and John B. Taylor, "Solution and Maximum Likelihood Estimation of Dynamic Nonlinear Rational Expectations Models," Econometrica, July 1983, 51 (4), 1169-1185. 
Giersch, Herbert, Karl-Heinz Paqué, and Holger Schmieding, "Openness, Wage Restraint, and Macroeconomic Stability: West Germany's Road to Prosperity 1948-1959," in Rudiger Dornbusch, Wilhelm Nolling, and Richard Layard, eds., Postwar Economic Reconstruction and Lessons for the East Today, Cambridge, MA: The MIT Press, 1993, pp. 1-27.

Gilchrist, Simon and John C. Williams, "Putty-Clay and Investment: A Business Cycle Analysis," Journal of Political Economy, October 2000, 108 (5), 928-960.

Greenwood, Jeremy and Boyan Jovanovic, "Accounting for Growth," in Charles R. Hulten and Michael J. Harper, eds., New Developments in Productivity Analysis, Chicago: University of Chicago Press, 2001.

, Zvi Hercowitz, and Per Krusell, "Long-Run Implications of InvestmentSpecific Technological Change," American Economic Review, June 1997, 87 (3), 342-362.

Hamada, Koichi and Munehisa Kasuya, "The Reconstruction and Stabilization of the Postwar Japanese Economy: Possible Lessons for Eastern Europe?," in Rudiger Dornbusch, Wilhelm Nolling, and Richard Layard, eds., Postwar Economic Reconstruction and Lessons for the East Today, Cambridge, MA: The MIT Press, 1993, pp. 157-187.

Hayashi, Fumio, "Is Japan's Saving Rate High?," Federal Reserve Bank of Minneapolis Quarterly Review, 1989.

Hulten, Charles R., "Introduction," in Charles R. Hulten, ed., Productivity Growth in Japan and the United States, Chicago: The University of Chicago Press, 1991, pp. 1-27.

Johansen, Leif, "Substitution versus Fixed Production Coefficients in the Theory of Economic Growth: A Synthesis," Econometrica, April 1959, 27 (2), 157-176.

King, Robert G. and Sergio T. Rebelo, "Transitional Dynamics and Economic Growth in the Neoclassical Model," American Economic Review, 1993, 83 (4), 908-931.

Kydland, Finn E. and Edward C. Prescott, "Hours and Employment Variation in Business Cycle Theory," Economic Theory, 1991, 1 (1), 63-81.

Maddison, Angus, Economic Growth in the West, London: Twentieth Century Fund, Allen and Unwin, 1964.

, Dynamic Forces in Capitalist Development, Oxford: Oxford University Press, 1991.

, Monitoring the World Economy, 1820-1992, Paris: Organization for Economic Co-operation and Development, 1995. 
OECD, National Accounts of OECD Countries, Paris: Organization for Economic Coopertaion and Development, various.

Ohkawa, Kazushi and Henry Rosovsky, "Postwar Japanese Growth in Historical Perspective: A Second Look," in Lawrence Klein and Kazushi Ohkawa, eds., Economic Growth, The Japanese Experience Since the Meiji Era, Homewood, IL: Richard D. Irwin, Inc., 1968, pp. 3-34.

Oliner, Stephen D. and Daniel E. Sichel, "The Resurgence of Growth in the Late 1990s: Is Information Technology the Story?," Journal of Economic Perspectives, Fall 2000, 14 (4), 3-22.

Parente, Stephen L. and Edward C. Prescott, "Barriers to Technology Adoption and Development," Journal of Political Economy, July 1994, 102 (2), 298321.

van Ark, Bart and Dirk Pilat, "Productivity Levels in Germany, Japan, and the United States: Differences and Causes," Brookings Papers on Economic Activity: Microeconomics, 1993, pp. 1-69.

Wallich, Henry C., Mainsprings of the German Revival, New Haven: Yale University Press, 1955.

Wolf, Holger C., "The Lucky Miracle: Germany 1945-1951," in Rudiger Dornbusch, Wilhelm Nolling, and Richard Layard, eds., Postwar Economic Reconstruction and Lessons for the East Today, Cambridge, MA: The MIT Press, 1993, pp. 29-56.

Wolff, Edward N., "The Productivity Slowdown: The Culprit at Last? FollowUp on Hulten and Wolff," American Economic Review, December 1996, 86 (5), $1239-1252$. 